\title{
Beiträge zur Kenntniss der Farbenblindheit.
}

\author{
Von
}

\section{Dr. Richard Hilbert}

in Königsberg i. Pr.

Wohl jeder Beobachter, welcher genau und sorgfältig eine grössere Anzahl von Farbenblinden untersucht hat, wird die Erfahrung gemacht haben, dass die von ihm untersuchten Farbenblinden (ich spreche in folgendem selbsstverständlich nur von Rothgrünblindheit, da die anderen Arten von Farbenblindheit wegen ihrer Seltenheit kaum in Betracht kommen) gewisse Verschiedenheiten unter einander zeigen, die sich sowohl in den Bezeichnungen, welche sie gefärbten Körpern ertheilen, dokumentiren, als auch namentlich bei der Wahlprobe nach Holmgren in der Zusammenstellung ibnen gleich gefärbt erscheinender Wollproben hervortreten. Diese Verschiedenheiten sind es, welche Holmgren, Donders und andere Forscher bewogen haben gemäss der YoungHelmholtz'schen Theorie eine Rothblindheit und eine Grünblindheit zu unterscheiden und daran festzuhalten, obwohl diese Theorie mit den an Farbenblinden gewonnenen Erfahrungen absolut nicht in Uebereinstimmung zu bringen ist, wohingegen die Hering'sche Farbentheorie trotz mancher Mängel derselben die Erscheinungen der Farbenblindheit in geradezu glänzender Weise zu erklären im Stande ist, und in ihren Grundprinzipien wohl als richtig und den Thatsachen entsprechend betrachtet werden darf.

Obwohl es nun nicht schwer ist nachzuweisen, dass ein nach Holmgren and Andern Rothblinder auch grünblind, respective ein Grünblinder auch rothblind ist, so blieben doch noch immer jene oben angedeuteten Differenzen bestehen, und zwar konnte man bei sorgfältiger Untersuchung nicht nur zwei Gruppen unterseheiden, die so zu sagen die Extreme darstellen, sondern es war auch noch eine dritte Gruppe ohne Schwierigkeit nachweisbar, welche die Eigenthümlichkeiten der beiden ersteren in sich ver- 
einigte und so zu sagen die Vermittlerrolle zwischen denselben spielte.

Nach Holmgren ${ }^{1}$ ) ist derjenige Farbenblinde, welcher bei der Wahlprobe zu purpur blau und violett legt rothblind, derjenige welcher zu purpur grau und grün legt, grïnblind. Obwohl es nun auch Holmgren bekannt ist, dass es eine grosse Anzahl Farbenblinder gibt, welche beide Arten von Verwechselungen begehen, so machte er der Young-Helmholtz'sehen Theorie zu Liebe doch keine dritte Gruppe aus den letztgenannten Farbenblinden, was doch eigentlich nahe lag, sondern dieselben wurden willkürlich der einen oder der andern Gruppe zuertheilt, eventuell die Diagnose unsicher gelassen.

Worauf aber die oben genannten Verschiedenheiten zwischen den einzelnen Farbenblinden beruhen, wurde mir bei Gelegenheit von Untersuchungen ${ }^{2}$ ) klar, welche ich anstellte, um den Einfluss fluorescirender Körper auf die Länge des Spektrums Farbenblinder zu erforschen. $\mathrm{Zu}$ diesem Zweck wurde in einem verdunkelten Ziminer auf einem Bogen Papier ein objektives Spektrum von stets gleicher Länge entworfen, und ich liess nun der Einfachheit halber jeden Farbenblinden die Grenzen seines Spektrums mit Bleistift auf dem Papier markiren. Dabei stellte es sich heraus (unter anderen Thatsachen), dass es Farbenblinde mit stark ver. kiirztem und wenig verkürztem Spektrum gebe (verkürzt ist dasselbe in jedem Falle) und dass dazwisehen alle möglichen Abstufungen vorhanden seien.

Die genauere Betrachtung der einzelnen Fälle lehrte nun, dass die stark verkürzten Spektra den Rothblinden nach Holmgren, die wenig verkürzten den Grünblinden angehörten und dass die mitteren Spektra jener oben charakterisirten dritten Gruppe entsprachen.

Nun dürfte es wohl keinem Zweifel unterliegen, dass die Verkürzung des Spektrums Hand in Hand gehe mit einer Verschiebung der Empfindung für jene Aetherschwingungen, welche wir mit dem Namen „Farben“ bezeichnen, eine Thatsache, welche

1) F. Holmgren, Die Farbenblindheit in ihren Beziehungen zu den Eisenbahnen und der Marine. Leipzig 1878. S. 136.

2) R. Hilbert, Das Verhalten der Farbenblinden gegenüber den Erscheinungen der Fluorescenz. Königsberg 1882. 
schon aus der Verschiebung der hellsten Stelle des Spektrums der Farbenblinden gegenüber der der Farbentiuchtigen hervorgeht. Aus diesem Grunde muss also die Farbenempfindung Farbenblinder mit stark verkürztem Spektrum eine andere sein als die solcher mit weniger oder sehr wenig verkürztem Spektrum: Kurz und gut, es gibt also Rotbgrünblinde mit stark verkürztem, mit mittelmässig verkürztem and mit wenig verkürztem Spektrum, and die Verschiedenheiten, die dieselben unter einander zeigen, sind eben durch die Länge ihres Spektrums bedingt.

Geissle ${ }^{1}$ ) gibt in der citirten Schrift sehr instruktive Abbildungen von diesen beiden extremen Arten von Spektren Farbenblinder, und es ist nur unbegreiflich, wie er, als Urheber jener, wie jeder sorgfältige Untersucher bezeugen kann, goldrichtigen Abbildungen, im Zweifel sein kann, welcher Farbentheorie die Palme zuzuerkennen sei,

Ein anderer Punkt, welcher ebenfalls von jedem aufmerksamen Beobachter bald bemerkt wird, und der namentlich bei Bestimmung der Sehschärfe für Farben auffällt, ist die ungemein grosse Empfindlichkeit Farbenblinder für Helligkeitsdifferenzen. In Fällen, wo ein farbentüchtiger Mensch sehr im Zweifel ist, welcher von zwei vorgelegten farbigen Körpern der hellere, welcher der dunklere sei, entscheidet der Farbenblinde schnell und sicher, und eine nachträglich vorgenommene genauere photometrische Untersuchung ergibt die Richtigkeit der Angaben desselben.

Selbstverständlich beruht dieses feine Unterscheidungsvermögen nicht auf einer besonders hervorragenden Ausbildung des Lichtsinnes, wie man sich durch diesbezügliche Untersuchungen leicht iiberzeugen kann, sondern es beruht meines Erachtens auf der Thatsache, dass die Helligkeit ungefärbter Gegenstände leichter za beurtheilen ist als die gefärbter und namentlich verschieden gefärbter. In dem Farbensystem des Farbenblinden fehlen nun zwei Hauptfarben und sämmtliche Mischfarben (da sich wie be-

1) A. Geissler, Die Farbenblindheit, ihre Prüfungsmethoden und ihre praktische Bedeutung. Leipzig 1882. 
kannt gelb und blan nicht mischen ohne sich aufzuheben). Aus diesen Grïnden erscheinen dem Farbenblinden eine Anzahl von Körpern, die für den Farbentuichtigen gefärbt sind, farblos, eine weitere Reihe, die dem Farbentïchtigen als verschiedenfarbig imponirt, einfarbig, und es ist daher bei einer grossen Menge von Objekten dem Farbenblinden leichter als dem Farbentüchtigen Helligkeitsdifferenzen unter denselben zu unterscheiden. Dieses scheint mir der einfache Grund des diesbeziiglichen Unterschiedes zwischen Farbenblinden und Farbentïchtigen zu sein.

\section{Veber das Verhältniss zwischen Reizdauer, Reiz- grösse und latenter Reizperiode nach einem neuen Versuchsverfahren.}

Von

\section{A. Guenhagen.}

Hierzu Tafel VI, Fig. 1 und 2.

Das Verhältniss, welches zwischen dem physiologischen Effeet einer electrischen Nervenreizung einerseits, Reizdauer und latenter Reizperiode andererseits theils wirklich nachgewiesen, theils mindestens behauptet worden ist, hat schon ofter's eingehenden Untersuchungen zum Vorwurfe gedient. Wenn ich dasselbe jetzt von Neuem zum Gegenstand der Betrachtung mache, so veranlasst mich dazn vornebmlich der Wunseb, das Versuchsverfahren zur allgemeinen Kenntniss zu bringen, dessen ich mich bereits seit längerer Zeit zu bedienen pflege, um die in Frage stehenden Beziehungen aufzuhellen, erst in zweiter Linie das Verlangen die Abweichungen festzustellen, welche in den von mir und von anderen gewonnenen Ergebnissen hervorgetreten sind.

Das Versuchsverfahren, dessen Beschreibung ich vorausschicken muss, ist seinem Principe nach bereits in dem von mir 